\title{
Osteoporosis in chronic obstructive pulmonary disease
}

\author{
A.A. Ionescu*, E. Schoon ${ }^{\#}$
}

Osteoporosis in chronic obstructive pulmonary disease. A.A. Ionescu, E. Schoon. (C) ERS Journals Ltd 2003.

ABSTRACT: Osteoporosis is one of the systemic effects associated with chronic obstructive pulmonary disease (COPD). Potential risk factors of osteoporosis may be due to the lifestyle, genetics, treatment with corticosteroids, endocrine abnormalities or the impairment of the body composition and peripheral skeletal muscles. Evidence for the possible contribution of such factors is reviewed.

The occurrence of fractures, as a consequence of osteoporosis, can contribute to the disability and mortality of patients with COPD and add to the economic burden of the disease. The treatment with corticosteroids for the lung disease is associated with increased prevalence of fractures, but other factors may contribute.

There is a remarkable paucity of interventional studies targeting the osteoporosis in patients with COPD. The results of studies on the treatment of osteoporosis in chronic lung diseases, some including small numbers of patients with COPD, are reviewed in the paper.

Prospective longitudinal studies on the incidence of osteoporosis in chronic obstructive pulmonary disease need to assess patients with various degrees of disease severity and investigate the possible contribution of etiological factors. Randomised placebo-controlled trials are required to assess the effect of intervention, such as bisphosphonates, hormone replacement, calcium supplementation, on the prevention and treatment of osteoporosis and fractures in chronic obstructive pulmonary disease.

Eur Respir J 2003; 22: Suppl. 46, 64s-75s.
* Section of Respiratory and Communicable Diseases, Dept of Medicine, University of Wales, College of Medicine, Llandough Hospital, Penarth, Wales, UK, "Catharina Ziekenhuis, Afdeling Interne Geneeskunde, Eindhoven, The Netherlands.

Correspondence: A.A. Ionescu, Section of Respiratory and Communicable Diseases, Dept of Medicine, University of Wales, College of Medicine, Llandough Hospital, Penlan Road, Penarth, CF64 2XX, Wales, UK. Fax: 442920716416

E-mail: ionescuaa@cardiff.ac.uk

Keywords: Chronic obstructive pulmonary disease

fractures

osteoporosis

osteopenia

Received and accepted June 302003
Chronic obstructive pulmonary disease (COPD) is a progressive disease of adulthood and older age. While the initial treatment is focused on relieving the symptoms due to the impairment of the lung function, a variety of systemic effects become obvious as the disease progresses [1-5]. Osteoporosis has been recognised as one of the systemic effects of COPD and debate continues on the precise mechanisms involved and on the options for treatment [6-8]. The etiology of osteoporosis in COPD is probably complex and various factors may contribute to its pathogenesis. Some of these are consequences of the chronic inflammatory lung disease and lung damage (reduced physical activity due to dyspnoea, reduced skeletal muscle mass and changes in body composition, systemic inflammation), of the therapy used during the disease (corticosteroid treatment), and of the natural changes due to ageing (hypogonadism, reduced muscle mass, inactivity). Environmental factors and habits from earlier in life also contribute to the pathogenesis of osteoporosis. When fractures occur as a complication of osteoporosis the quality of life of such patients, who are already restricted because of the lung disease, is further reduced. Therefore, awareness amongst healthcare providers and early diagnosis should trigger preventive and therapeutic measures that could avoid or reduce the consequences of osteoporosis.

\section{Definitions}

Osteoporosis is a systemic skeletal disease characterised by microarchitectural reduction of bone tissue leading to a low bone mass, increased bone fragility and thereby increased fracture risk [9]. The preclinical state of osteoporosis is called osteopenia. Osteoporosis is commonly found in postmenopausal females and elderly subjects, or as a consequence of chronic disease or medical treatment. Different methods of bone mineral density (BMD) measurements can be used. Dual energy X-ray absorptiometry (DXA) is currently the most frequently used and is accurate, reproducible and involves very low doses of radiation. BMD is expressed in standard deviation of means, the $\mathrm{T}$ and $\mathrm{Z}$ scores. The $\mathrm{T}$ score is a standard deviation compared to a young adult sex-matched control population. The $\mathrm{Z}$ score is a standard deviation compared to an age- and sex-matched control population. One standard deviation reduction in the BMD increases the fracture risk by $1.5-3$ fold [10].

\section{Epidemiology}

Large epidemiological trials aimed to assess the incidence and prevalence of osteoporosis within populations of patients with COPD at various stages of disease severity are lacking. Information about the frequency of osteoporosis associated with COPD is available mainly from assessments before lung transplantation in patients with severe disease and from studies on the use of corticosteroid treatments in COPD (table 1).

In a group of 15 patients with COPD referred for lung transplantation $7(45 \%)$ had bone $\mathrm{Z}$ scores of $>2$ SD below the mean [11]. Patients with cystic fibrosis (CF) referred for lung transplantation had greater frequency of osteoporosis $(75 \%)$ 
Table 1.-Epidemiology of osteoporosis and fractures in chronic obstructive pulmonary disease (COPD)

\begin{tabular}{|c|c|c|c|c|}
\hline 1st author [ref no.] & $\begin{array}{l}\text { Year of } \\
\text { study }\end{array}$ & Patients' characteristics & Number of patients & Main outcome \\
\hline ARIS [11] & 1996 & Pretransplantation & 15 & $\begin{array}{l}\mathrm{Z} \text { score }>2 \mathrm{SD} \text { below mean } \\
(7 \text { patients })\end{array}$ \\
\hline SHANE [12] & 1996 & Pretransplantation & 28 & $\begin{array}{l}29 \% \text { prevalence of vertebral } \\
\text { fractures }\end{array}$ \\
\hline Dubois [13] & 2002 & $\begin{array}{l}\text { Continuous }(\mathrm{n}=11) \text {, intermittent } \\
(\mathrm{n}=38) \text { systemic } \mathrm{CS} \text { or inhaled } \\
\text { CS }(\mathrm{n}=37)\end{array}$ & 86 & $\begin{array}{l}\text { Osteoporosis: } 21 \% \text { (lumbar } \\
\text { spine), } 22 \% \text { (hip) and } 28 \% \\
\text { (femoral neck) }\end{array}$ \\
\hline $\begin{array}{l}\text { Lung Health Study } \\
\text { research Group [14] }\end{array}$ & 2000 & $\begin{array}{l}\text { FEV1 range } 30-90 \% \text { pred; inhaled } \\
\text { triamcinolone }(n=158) \text { or placebo } \\
(n=170)\end{array}$ & 412 (BMD measured) & $\begin{array}{l}\text { BMD reduction over } 3 \text { yrs } \\
\text { greater at lumbar spine } \\
\text { and femoral neck for } \\
\text { triamcinolone than for } \\
\text { placebo. }\end{array}$ \\
\hline PAUWELS [15] & 1999 & $\begin{array}{l}\text { Smokers with mild COPD } \\
\text { randomised to inhaled } \\
\text { budesonide or placebo }\end{array}$ & $\begin{array}{c}102 \text { (BMD measured) } 653 \\
\text { had spine radiographs }\end{array}$ & $\begin{array}{l}\text { No greater BMD decline over } \\
3 \text { yrs in the budesonide } \\
\text { group compared to placebo. } \\
\text { At least } 1 \text { vertebral fracture in } \\
13.4 \% \text { (budesonide) and } \\
11.5 \% \text { (placebo). }\end{array}$ \\
\hline MCEvoY [7] & 1998 & $\begin{array}{l}\text { FEV } 1 / \mathrm{FVC}<70 \% \text { in } 3 \text { groups: } 1 \text { ) } \\
\text { no CS; } 2 \text { ) inhaled CS; } 3 \text { ) } \\
\text { systemic CS }\end{array}$ & 312 & $\begin{array}{l}\text { Prevalence of vertebral fractures } \\
\quad \text { (\%): } 48.7 \text { (group 1), 57.1 } \\
\quad \text { (group 2), } 63.3 \text { (group 3). }\end{array}$ \\
\hline RIANCHO [16] & 1987 & Mean FEV1 39\%, no long-term CS & 44 & $\begin{array}{l}5.3 \% \text { wedged vertebra ( }>30 \% \\
\text { height loss), not different from } \\
\text { the control group }(7.4 \%) \text {. }\end{array}$ \\
\hline
\end{tabular}

CS: corticosteroids; FEV1: forced expiratory volume in one second; FVC: forced vital capacity; BMD: bone mineral density; pred: predicted.

than the COPD patients in the group studied by the same authors, while only $15 \%$ of those with other pulmonary disease had osteoporosis. Not surprisingly, of the 12 fractures that occurred in 45 patients after transplantation, six were found in patients with COPD and the rest in those with CF. A similar finding was reported in another group of 28 patients with COPD awaiting lung transplantation who had significantly lower BMD at the femoral neck site, which was only matched by patients with $\mathrm{CF}$ but not by those with other severe lung disease in the pre-transplantation group [12]. The same authors reported a $29 \%$ prevalence of vertebral fractures in the pre-transplantation patients with COPD.

In a study on 86 male patients with COPD receiving various regimes of corticosteroid treatments or none at all, osteoporosis was found in $21 \%$ at lumbar spine, $22 \%$ at the hip and $28 \%$ at femoral neck [13]. In a study on 44 male patients with COPD, of which 19 received long-term oral corticosteroid treatment, a low BMD was found at the radial and vertebral bones in those treated with prednisolone, while a reduced trabecular BMD was also found in those who did not receive long-term corticosteroid treatment [8].

In a large multicentre randomised placebo-controlled trial (1,116 patients with COPD) on the effects of inhaled triamcinolone acetonide, in the group of 412 participants who had BMD measured at the beginning of treatment and $3 \mathrm{yrs}$ later, those taking triamcinolone had significantly greater reduction in $\mathrm{BMD}$ at the lumbar spine $(\mathrm{p}<0.007)$ and femoral neck $(\mathrm{p}<0.001)$ than those receiving placebo [14]. The 3 yrs assessment found a mean \pm SD $2.0 \pm 0.35 \%$ reduction in BMD at the femoral neck in those treated with triamcinolone compared to only $0.22 \pm 0.32 \%$ in those receiving placebo [14]. In contrast to these findings, another multicentre double-blind randomised placebo-controlled study on 1,277 smokers with mild COPD found no significant change in BMD over 3 yrs in the 102 patients who had BMD measured and received inhaled budesonide compared to the 92 patients receiving placebo [15]. A modest reduction in BMD at the trochanter site $(0.38 \%)$ in the budesonide group compared to $0.04 \%$ in the placebo group $(\mathrm{p}=0.02)$ was reported [15].

The above research suggests that osteoporosis is found in a proportion of patients with COPD and confirms the view that long-term epidemiological studies which would take into account various stages of the disease are required in order to identify the patients who have a high risk to develop osteoporosis.

\section{Potential risk factors to the development of osteoporosis in chronic obstructive pulmonary disease}

It is likely that osteoporosis in patients with COPD is a consequence of various factors some having been present throughout the life of the patient, others due to the disease process itself and some specific to the treatment of the lung disease (table 2).

Table 2.-List of potential risk factors of osteoporosis and main references

\begin{tabular}{lc}
\hline Factor & Reference \\
\hline Smoking & $17-23$ \\
Increased alcohol intake & $19-22$ \\
Vitamin D levels & 12,16 \\
Genetic factors & $20,24-28,29,30$ \\
Treatment with corticosteroids & $1,7,8,13-15$, \\
& $31,32,33,34-44$ \\
Reduced skeletal muscle mass and strength & $44-53$ \\
Low BMI and changes in body composition & $54-63$ \\
Hypogonadism & $64-69$ \\
Reduced levels of insulin-like growth factors & $70,71,72$ \\
Chronic systemic inflammation & 73
\end{tabular}

BMI: body mass index. 


\section{Smoking and other lifestyle factors}

Smoking has been recognised as a contributing factor to bone loss for more than two decades [17, 18]. The risk of spinal osteoporosis was greater in males who smoked (relative risk $2.3, \mathrm{p}=0.01$ ) than in nonsmokers and the risk increased by 1.009 per pack-yr smoked [19]. Moreover, the bone loss over a period of 16 yrs was greater for males who smoked any number of cigarettes $\left(0.104 \mathrm{~g} \cdot \mathrm{cm}^{-1}\right)$ than for nonsmokers $\left(0.072 \mathrm{~g} \cdot \mathrm{cm}^{-1}, \mathrm{p}=0.03\right)$ and even greater for smokers of $>2$ packs per day $\left(0.114 \mathrm{~g} \cdot \mathrm{cm}^{-1}\right)$ [20]. Notably, this study does not report the forced expiratory volume in one second (FEV1) for smokers, therefore it is not known if any of the subjects had COPD.

In 341 male subjects aged between $40-80$ yrs smoking added to the bone loss due to ageing [21]. In this wide range of ages, the current smokers had a lower per cent of bone cortical areas than those who never smoked. In a multiple regression analysis, after adjustment for the initial percentage of cortical area, both age $(\mathrm{p}=0.005)$ and smoking $(\mathrm{p}=0.03)$ were inversely related to the per cent cortical area [21].

In a prospective study over 3.5 yrs 84 peri- and postmenopausal females were followed up, of which 63 were nonsmokers, eight smoked $<20$ pack-yrs and 13 smoked $>20$ pack-yrs [22]. Allowing for the small numbers of smokers included in the study, the authors found that after correcting for age and body mass index (BMI) heavy smokers had lower bone mineral content at the distal radius and lower BMD at the lumbar spine, while the same parameters were not different between light smokers and nonsmokers. The authors speculate that their findings together with previous reports of increased fractures in smokers would support the hypothesis that heavy smokers who start this habit early in their life have a deficit in the peak bone mass [22]. This issue has been addressed in a prospective cohort study on the lifestyle factors which may influence the peak bone mass on 264 healthy subjects who were followed up from the ages of between 9 and 18 to the ages of 20 to 29 at completion of the study [23]. The age of participants at the end of the study allowed assessment of the peak bone mass. Males who smoked had a $9.7 \%$ lower BMD at the femoral neck compared to nonsmokers. In addition to the effect of smoking on the deficit of peak bone mass, the level of regular exercise was the single most important determinant of peak bone mass (BMD at femoral neck was up to $10 \%$ greater in those who exercised regularly). In addition, increased calcium intake contributed by a $4.7 \%$ increase in BMD at the femoral neck only in females [23].

Increased alcohol intake is an independent risk factor for osteoporosis [20, 22]. One hundred and eleven males had bone loss assessed over 16 yrs by single photon absorptiometry on the midshaft radius and a greater bone loss $\left(0.105 \mathrm{~g} \cdot \mathrm{cm}^{-1}\right)$ was found in those who had $>1.5$ drinks per day (mean $95.5 \mathrm{~g}$ alcohol per week) than in those who did not drink $\left(0.062 \mathrm{~g} \cdot \mathrm{cm}^{-1}\right)$ [20]. The risk for vertebral fractures due to osteoporosis was greater for males who drank (relative risk 2.4, $\mathrm{p}=0.02$ ) than for those who did not and it was 1.007 greater per ounce-year of drinking $(\mathrm{p}=0.02)$ [19].

The influence of lifestyle factors that determine the peak bone mass in early adulthood and affect the BMD during later life could explain why some patients with COPD have a greater risk to develop complications of severe osteoporosis when exposed to additional risk factors, such as corticosteroid treatments for the lung disease.

\section{Vitamin D}

Vitamin D regulates the absorption of calcium, parathyroid hormone secretion and bone resorption [74]. A few studies reported low levels of vitamin D in some patients with COPD. In a group of 44 males with COPD $27 \%$ had serum concentrations of 25 hydroxyvitamin D $(25(\mathrm{OH})$ vitamin D) less than the lowest value for the healthy subjects, while the biochemical markers of bone metabolism did not differ in these patients compared to those with normal vitamin D levels [16]. Another group reported reduced serum $25(\mathrm{OH})$ vitamin $D$ in 10 of their 28 patients with severe COPD awaiting lung transplantation but the serum level of the active metabolite 1,25 dihydroxyvitamin $\mathrm{D}$ was within the expected range in these patients and no difference in BMD was found between patients with a low or a normal $25(\mathrm{OH})$ vitamin D level [12].

\section{Genetic factors}

There is evidence that monozygotic twins have greater concordance of the BMD than other siblings [24, 25]. However, some environmental risk factors for osteoporosis such as the levels of physical activity, smoking and the amount of alcohol intake were similar in monozygotic twin pairs, while differences were found in dizygotic twin pairs [20]. Therefore the assessment of the contribution of genetic factors and of environmental factors to the development of osteoporosis can be hazardous. Some researchers have investigated the polymorphism of the genes encoding receptors for vitamin $\mathrm{D}$ or oestrogens and the genes for collagen type I or interleukin (IL)-6 (a cytokine involved in the differentiation of osteoclasts) [24, 26-28]. While there is still considerable controversy on the genetic determinism of osteoporosis $[24,75]$, the most promising finding remains the identification of a polymorphism in the gene COLIA 1 which encodes the type I collagen and mutations of this gene have been associated with a low BMD [29, 30].

\section{Systemic and inhaled corticosteroid treatment}

Treatment with corticosteroids is prescribed in patients with COPD in order to improve the obstructive syndrome, alleviate the shortness of breath and the associated discomfort and there is evidence that such treatment is not only beneficial but sometimes even lifesaving [76, 77]. A meta-analysis on the use of oral corticosteroid treatment (prednisolone between $30 \mathrm{mg} \cdot \mathrm{day}^{-1}$ for 7 days and $60 \mathrm{mg} \cdot \mathrm{day}^{-1}$ tapered to $20 \mathrm{mg} \cdot \mathrm{day}^{-1}$ over 8 weeks) in patients with stable COPD found an effect size from $0-38 \%$, depending on the outcome measures $(0 \%$ when the outcome measures were arterial blood gas, carbon monoxide diffusing capacity of the lung, or subjective changes, 38\% when outcome was assessed by the 12-min walking distance, peak expiratory flow rate and dyspnoea score) [76]. When the authors of the meta-analysis averaged the effect size and used FEV1 as criterion, it became obvious that oral corticosteroid therapy had a $20 \%$ improvement effect $(10 \%$ more than for the placebo group) [76].

A prospective, randomised controlled trial on the use of oral corticosteroids in patients admitted to hospital for exacerbations of COPD found that the per cent change of the post-bronchodilatation FEV1 was twice greater in the group treated with corticosteoids compared to placebo $(\mathrm{p}<0.001)$ and after 5 days of treatment the absolute FEV1 increased three times in the same group $(p=0.039)$ [77]. Moreover, the number of days in hospital was shorter for the corticosteroid-treated group $(p=0.027)$. Despite these beneficial effects on the lung function and the well being of the patient, the use of corticosteroids is associated with various side effects, one of which is osteoporosis $[1,7,31]$. 
Corticosteroids reduce the absorption of calcium in the gut, increase the renal excretion of calcium, and stimulate the bone resorption (probably through the effect of parathormone) [78-80]. In addition, corticosteroids reduce the bone formation by directly inhibiting the osteoblastic line, as well as secondary to the hypogonadism associated with the excess of corticosteroids [78]. Most of the corticosteroid-induced bone loss occurs in the trabecular bone (proximal femur, mainly Ward's triangle) and cortical rim of the vertebral bodies [80-82]. Bone biopsies from patients receiving corticosteroid treatment showed reduced trabecular bone, increased resorption cavities and reduced numbers of osteoblasts [78, 83, 84].

Research into the COPD-related osteoporosis has assessed the use of oral corticosteroids, as well as the different types of inhaled corticosteroid treatments, the length, dosage and delivery systems, and have used as outcome measures BMD, the concentrations of bone formation and resorption markers, as well as the rate of fractures. In males with chronic bronchitis and a mean \pm SD FEV1 of $41 \pm 19 \%$ receiving oral corticosteoids for at least $1 \mathrm{yr}$ the circulating levels of osteocalcin were reduced $(\mathrm{p}<0.01)$ compared to reference values, but the levels were also low $(p<0.05)$ in those not taking long-term oral corticosteroids [8]. The vertebral BMD was low in both COPD groups (patients who were not taking long-term oral corticosteroids had received intermittent courses), while those on oral corticosteroids had in addition a reduced $\mathrm{BMD}$ at the radius.

Patients who received repeated treatments with prednisolone for exacerbations of COPD, in a cumulative dose of $>1$ gram, had reduced BMD at the spine $(\mathrm{p}<0.001)$, after correction for FEV1 and BMI, compared to a control group [13]. The patients who received continuous prednisolone or intermittent courses in a cumulative dose of $<1$ gram had a better preserved BMD at the spine and other sites. The authors did not measure bone resorption or formation markers, therefore their comment that in patients with repeated courses of systemic corticosteroids rapid bone loss occurs after each treatment while in the long-term treatment group a plateau might be achieved, needs to be assessed in further studies.

A reduction in the blood concentration of osteocalcin occurred in healthy subjects treated with high or low doses of prednisolone or with inhaled budesonide after the first week of treatment, and no further reduction after a second week of the same treatment was found [32]. This suggests a rapid effect of both oral and inhaled corticosteroids on the blood concentration of osteocalcin. A rapid reduction of bone formation assessed by the blood concentration of osteocalcin was confirmed in healthy subjects taking $15 \mathrm{mg}$ prednisolone or $1 \mathrm{mg}$ inhaled beclomethasone for 1 week [33]. After treatment a mean reduction of $42 \%$ of the circulating osteocalcin occurred in the prednisolone group, the concentration being close to that measured in asthma or COPD patients on long-term prednisolone ( $>7.5 \mathrm{mg}$ daily), while in the beclomethasone group a $17 \%$ fall in the osteocalcin concentration was reported [33].

Despite some concern on the lack of international standards for the assays used to measure osteocalcin concentrations [85], the above studies support the view that for doses of corticosteroids which have an effect on bone resorption markers, this occurs very soon after the exposure to the drug has started. Controversy still exists on the relationship between these rapid changes in bone markers and the long-term bone loss. Osteocalcin and procollagen type I carboxyl terminal propeptide (PICP) (bone formation markers) and type I collagen carboxy terminal telopeptide (ICTP) (marker of bone resorption) were measured after 4 weeks of treatment with at least $800 \mu \mathrm{g}$ inhaled budesonide or beclomethasone in a group of patients with mild asthma or
COPD [34]. The authors report a decline in osteocalcin, a rise of the concentration of PICP and of the ratio PICP to ICTP [34]. However, the same researchers reported no difference from baseline in PICP after 2.5 yrs of treatment with beclomethasone $800 \mu \mathrm{g} \cdot \mathrm{day}^{-1}$ for airways obstruction [34, 35].

Another group studied patients with moderate-to-severe asthma treated with 2 different regimes of inhaled corticosteroids or inhaled and oral corticosteroids and measured markers of bone formation and resorption every 3 months for 24 months [36]. The reported 3 monthly measurements of osteocalcin (bone formation) and deoxypyridinoline (bone resorption) show considerable variability between some assessment times. The study concluded that neither the bone formation nor the bone resorption markers changed significantly after 2 yrs compared to baseline [36]. This suggests that short-term changes in such bone markers need to be interpreted cautiously.

While controversy persists on the relationships between short- and long-term changes in the bone turnover markers several studies have reported a loss of BMD after treatment with corticosteroids. When the effect of inhaled corticosteroids on the bone density and bone markers were assessed, the type, dose and possibly form of delivery of the treatment had an effect on the BMD [14, 15, 31, 34-42]. However, results from various studies are difficult to compare with each other because of the study population (asthma and COPD pooled together in some), different outcome measurements and length of time between initial and final assessments. In patients with asthma quantitative computed tomography analysis of vertebral trabecular BMD found a reduced BMD after $12(\mathrm{p}=0.006)$ and 24 months $(\mathrm{p}=0.004)$ treatment with beclomethasone $2 \mathrm{mg} \cdot \mathrm{day}^{-1}$ compared with fluticasone $1 \mathrm{mg} \cdot \mathrm{day}^{-1}$, while BMD at the spine and femoral neck by DXA were unchanged in both treatment groups [36]. The BMD measured on patients with asthma treated with high dose of inhaled beclomethasone $\left(1-2 \mathrm{mg} \cdot \mathrm{day}^{-1}\right.$ for at least $1 \mathrm{yr}$ ) and repeated short courses of oral corticosteroids for exacerbations was similar to the BMD of patients who were treated with inhaled corticosteroids and regular oral prednisolone (dose 5-30 mg.day ${ }^{-1}$ ) for between 1 and $25 \mathrm{yrs}$ [37].

However, another group reported no decline in the BMD in patients with moderate or severe asthma treated with daily inhaled $1 \mathrm{mg}$ fluticasone or $1.6 \mathrm{mg}$ budesonide delivered through volume spacer, for 12 months [38]. Patients with mild-to-moderate COPD treated with inhaled triamcinolone acetonide $1.2 \mathrm{mg} \cdot \mathrm{day}^{-1}$ were followed up for a mean of 40 months [14]. A significant reduction in BMD at the lumbar spine $(p=0.007)$ and femoral neck $(p<0.001)$ compared to placebo was reported [14]. Patients with mild COPD treated with $800 \mu \mathrm{g}$ budesonide for $3 \mathrm{yrs}$ had no reduction in BMD compared to placebo [15].

A review of the long-term studies on the association of bone loss in patients with asthma treated with inhaled corticosteroids concluded that while the cumulative dose for adverse effects on bone may vary according to the type of drug used, daily doses $<800 \mu \mathrm{g}$ of beclomethasone or budesonide and $<750 \mu \mathrm{g}$ of fluticasone have limited effects on bone metabolism [43]. In a study on 71 male patients with moderate-to-severe COPD who did not receive any formulation of corticosteroids, hypercapnic patients had lower total and trabecular BMD $(\mathrm{p}<0.001)$ and greater serum concentration of carboxy-terminal cross-linked telopeptide (bone resorption marker, $\mathrm{p}<0.05)$ than those with normocapnia and comparable FEV1/vital capacity and BMI [44].

Treatment with corticosteroids is a contributory factor to the pathogenesis of osteoporosis in COPD, but other aspects of the disease are probably linked to the loss of BMD. 


\section{Reduced peripheral skeletal muscle mass and strength}

Skeletal muscle dysfunction in COPD is probably multifactorial. The reduced mobility due to shortness of breath, the myopathy due to corticosteroid treatments and metabolic factors generate a vicious circle more obvious in patients with severe disease [45-47]. The force generated by the skeletal muscles during voluntary contractions has an important role in the postnatal development of the bone. The muscle strength increases with growth in childhood and declines in adulthood. It is usually followed by age-related changes in the bone mass [48]. The physiological process of ageing is accompanied by a decline in the skeletal muscle mass, referred to as sarcopenia, where the progressive reduction of the diameter of the muscles and of the number of muscle fibres is associated with a decline in the muscle strength [49, 50]. Both the muscle mass and strength are related to BMD [50, 51]. In the elderly sarcopenia and the muscle weakness are associated with increased rates of falls and hip fractures [52, 53]. The close relationship between the skeletal muscle strength and the bone mass is supported by the beneficial effects of resistance training on BMD [86]. The greater the stress on a bone area, the greater the bone mass, therefore the mechanical stress applied to the bone during training increases the BMD [87]. Resistance training for $1 \mathrm{yr}$ increased BMD by $1 \%$ at the lumbar spine and femoral neck in postmenopausal females, while in the control group a decrease of $1.8 \%$ (lumbar spine) and $2.5 \%$ (femoral neck) occurred [88].

Patients with COPD are at risk to develop osteoporosis due to a reduced skeletal muscle mass and strength, both secondary to the disease and due to the natural process of ageing. It remains for future research to assess if training of various skeletal muscle groups improve BMD or prevent the progressive loss of bone mass.

\section{Body mass index and changes in body composition}

Weight loss and a low BMI are predictors of mortality in patients with COPD [2, 17]. A preferential depletion of fatfree mass (FFM) has been reported in COPD and associated with increased exacerbations and hospital admission rates [3, $89,90]$. Moreover, a regional loss of muscle mass is predictive of mortality in patients with COPD and a FEV1 of $<50 \%$ [91]. Bone mass is related to FFM in males [92], while in females some investigators reported a relationship between fat mass (FM) and bone density [54, 55] and others between both FM and FFM and bone density [56, 57].

The relationship between FM and/or FFM and bone mass suggests that the load of soft tissues is important in the preservation of bone mass. In underweight elderly the bone mineral content was reduced compared to age-matched subjects with a normal BMI [58, 59]. Both the BMI and the mid arm muscle circumference (an index of FFM) were associated with a reduced BMD in a cross sectional study on 100 patients with COPD [60]. Other groups reported positive relationships between the BMI and the bone mass in patients with COPD, with correlation coefficients between 0.34 $(\mathrm{p}<0.05)$ and $0.57(\mathrm{p}<0.01)[61,62]$. Patients with severe COPD admitted for a rehabilitation programme had similar weight and height to a healthy age-matched control group. However, the patients had a low FFM by DXA $(\mathrm{p}<0.05)$ and this was accompanied by a reduced whole-body BMD $(\mathrm{p}<0.001)$ and BMD of the arms $(\mathrm{p}<0.05)$, legs $(\mathrm{p}<0.01)$ and trunk $(\mathrm{p}<0.01)$ [63].

Such studies support the view that weight loss and mainly the depletion of FFM are factors contributing to the loss of BMD in some patients with COPD.

\section{Hypogonadism and other endocrine abnormalities}

Hypogonadism and the reduced availability of sex hormones, either due to ageing or to the effect of corticosteroid treatment, contribute to the development of osteoporosis. Oestrogen deficiency in females increases the bone loss after menopause, and the decline in circulating free oestrogen in elderly males has also been related to a reduction in bone mass [64-67, 75]. Oestrogen regulates both bone resorption and formation, while testosterone regulates bone formation $[65,68,75]$. In addition to these age-related changes, corticosteroids alter the secretion of the gonadal hormones by reducing the secretion of the pituitary luteinizing hormone and of the circulating oestrogen and testosterone levels [80]. Males with severe COPD receiving oral corticosteroids (mean dose of prednisolone $9.4 \mathrm{mg} \cdot \mathrm{day}^{-1}$ ) had serum levels of free testosterone below normal and these were related to the dose of corticosteroid treatment $(\mathrm{r}=-0.54, \mathrm{p}=0.007)$ and to $\mathrm{BMI}$ $(r=0.24, p=0.037)$ [68]. Treatment with testosterone for 12 months in asthmatic males receiving long-term oral corticosteroids improved the BMD at the lumbar spine by $5 \%$ ( $p=0.005$ compared to the placebo group) and the FFM by 0.9 $\mathrm{kg}(\mathrm{p}=0.02$ compared to placebo) [69].

Another group of hormones with a potential role in osteoporosis are the insulin-like growth factors (IGF-1, its tissue ligands, the binding proteins IGFBP $1-6$ and receptors) [70]. IGF-1 and IGFBP 5 stimulate the differentiation and proliferation of osteoblasts [93]. The bone concentrations of IGF-1 and IGFBP-5 (which enhances the effect of IGF-1) decline with age and there is evidence of a parallel decline of their serum concentrations, despite the continuing controversy on the relationship between serum and bone concentration of these hormones [94, 95]. In addition, IGFs stimulate the synthesis of proteins and there is a reduced expression of IGF-1 gene during fasting and catabolism $[2,96]$. It has been hypothesised that the down-regulation of IGF-1 messenger ribonucleic acid (mRNA) expression found in the skeletal muscle is related to the muscle atrophy in some patients with COPD [71]. Low serum levels of IGF-1 have been reported in elderly with hip fractures and a low BMD [72]. These studies suggest that IGF-1 may influence bone mass directly or through its role in the preservation of the skeletal muscle mass. Both mechanisms may be of relevance in COPD and further research is needed to find out if in addition to the agerelated decline in IGF-1 there is any link between the IGF-1 activity on the bone and skeletal muscles and the pathogenesis of osteoporosis.

\section{The potential role of the chronic systemic inflammation}

Increased concentrations of the circulating inflammatory mediators (tumour necrosis factor (TNF)- $\alpha$, IL-6) have been reported in COPD, mainly in patients who lose weight and in those with a low FFM and skeletal muscle mass [3, 5, 97, 98]. Moreover, peripheral monocytes from patients with COPD who lose weight had an increased ability to produce TNF- $\alpha$ [99]. Leukocyte-derived IL- $\alpha$ and TNF- $\alpha$ stimulate bone resorption $[64,100,101]$ and IL-6 stimulates the formation of osteoclasts [102]. Peripheral macrophages from patients with idiopathic osteoporosis and rapid bone turnover produce increased amounts of IL-1 [73]. There is some evidence for a possible role of the inflammatory mediators on bone metabolism in COPD, which has been described in other 
diseases associated with weight loss, depletion of FFM and systemic inflammation such as chronic heart failure, cystic fibrosis or cancer [103-105].

Further research is required to evaluate if there is a relationship between the increased blood concentrations of some inflammatory mediators and the bone loss in COPD, and if such circulating inflammatory mediators are active at a tissue level and involved in other effects such as the muscle wasting and cachexia.

\section{Consequences of osteoporosis in chronic obstructive pulmonary disease: the risk of fractures}

Debate continues on the precise mechanisms and pathophysiology of osteoporosis in COPD, but most physicians are concerned about the risk of fractures, which would add to the disability of such patients (table 1). In a general population, a British epidemiological study reported that the two main independent factors for increased risk of hip fractures in the elderly were inactivity and muscle weakness [106]. The American National Health and Nutrition Examination Survey (NHANES) III found that weight loss of at least $10 \%$, a low phalangeal bone density and the presence of any chronic condition were main factors, with smoking and low physical activity levels additional risk factors for hip fractures in White males [107]. Such risk factors reported in a general population are likely be found in patients with COPD, who smoked or continue to smoke, are inactive and have weak skeletal muscles.

Fifty per cent of the patients with various disease treated with corticosteroids suffer fractures and the proportion is close to $100 \%$ in those treated for rheumatoid arthritis [78, 108-110]. A report on the use of oral corticosteroids and the risk of fractures, where $40 \%$ of patients were treated for respiratory disease found an increased rate of nonvertebral and hip fractures compared to the control group (relative rates $(95 \%$ confidence interval (CI)) were $1.33(1.29-1.38)$ and 1.61 (1.47-1.76), respectively) [108]. The relative rate of nonvertebral fractures increased with the dose of corticosteroids from 1.17 in the low dose $\left(<2.5 \mathrm{mg} \cdot\right.$ day $\left.^{-1}\right)$ to 1.64 in the high dose group (at least $7.5 \mathrm{mg} \cdot \mathrm{day}^{-1}$ ) and most of the excess risk of fractures disappeared within $1 \mathrm{yr}$ when the treatment was stopped [108].

A retrospective study on the risk of fractures in patients receiving inhaled corticosteroids, which included a $6 \%$ sample of the UK population and excluded patients with any confounding variables for fractures, reported a similar risk in patients who used inhaled corticosteroids and in those who received inhaled bronchodilators only, which suggests a role played by the chronic respiratory disease itself as a risk factor for osteoporosis [111]. In both groups the risk of fractures was higher than in the control group, and the relative risk increased with the dose of inhaled corticosteroid treatment (beclomethasone in $86.4 \%$ of cases) from 0.95 $(95 \%$ CI $0.67-1.34)$ if $<300 \mu \mathrm{g} \cdot \mathrm{day}^{-1}$ to $1.77(1.31-2.40)$ if $>700 \mu \mathrm{g} \cdot \mathrm{day}^{-1}[111]$. In asthma the use of continuous longterm oral corticosteroids was associated with $11 \%$ fractures of ribs and vertebrae, compared with no fractures in a group treated with intermittent oral corticosteroids [112]. Compared to the risk of fractures in post-menopausal females where for one SD reduction in BMD the risk doubles [113], in patients with asthma treated with long-term corticosteroids the risk of fractures was associated with greater BMD (osteopenia range) [114].

A cross-sectional study on 312 males with COPD assessed the prevalence of fractures in three groups: 1) patients who never used corticosteroids, 2) patients who received inhaled corticosteroids and 3 ) those receiving systemic steroids (range of the duration of corticosteroid treatments in group 3 was 2.5 to 1,300 weeks) [7]. The prevalence of at least one vertebral fracture was $48.7 \%$ in group $1,57.1 \%$ in group 2 and $63.3 \%$ in group 3 , with $\geqslant 6$ vertebral fractures found only in group 3 . The high risk of fractures in the group who never used corticosteroids suggests that factors others than the treatment may be involved in the pathogenesis of osteoporosis. However, a study on a smaller number of patients with COPD and severe lung disease found no evidence of an increased risk of fractures in patients who were not receiving long-term corticosteroid treatment [16], which suggests the need for further large prospective studies in order to investigate which patients with COPD are more at risk of fractures due to osteoporosis.

The occurrence of fractures has implications for the morbidity and mortality. Severe osteoporosis with thoracic vertebral fractures and wedging with hyperkyphosis was associated with about $10 \%$ reduction in forced vital capacity (FVC) in females, with a cumulative effect of the number of fractures on the decline in FVC [115]. Such a reduction in FVC would add to the lung function impairment and disability in patients with chronic lung disease. Mortality after hip fractures in the elderly is about $20 \%$ in the first year (highest mortality rate for any fractures) and 19\% of these patients require residential care when discharged from hospital, which adds to the economic burden of the disease [116, 117].

\section{Therapeutic interventions for osteoporosis in patients with chronic lung disease}

Despite the remarkable lack of interventional studies targeting osteoporosis in patients with COPD, some conclusions can be drawn from the treatment of corticosteroidinduced osteoporosis, postmenopausal osteoporosis and the few studies on patients with asthma and other chronic lung diseases.

\section{Calcium and vitamin D supplements}

In postmenopausal females calcium and vitamin D supplements may be beneficial if the dietary intake of calcium is low, which has been reported in some elderly females [118-120]. Some studies on corticosteroid-induced osteoporosis have reported that calcium and vitamin $\mathrm{D}$ supplements may reduce the rate of bone loss in the short term, but no increase of bone mass in the long term was found. Current recommendations suggest a minimum daily intake of $1,200 \mathrm{mg}$ of calcium in adults older than $50 \mathrm{yrs}$ and $1,500 \mathrm{mg}$ per day with vitamin D3 $400 \mathrm{IU} \cdot \mathrm{day}^{-1}$ if glucocorticoid-induced osteoporosis is diagnosed [43, 80, 121].

\section{Hormone replacement}

In postmenopausal females oestrogen-replacement therapy reduced the rate of fractures and this effect was more beneficial if the treatment was initiated early when menopause had started [118, 120, 122, 123]. In glucocorticoid-induced osteoporosis in females oestrogen and progesteron treatment reduced the speed of bone loss [124]. In males with asthma receiving long-term corticosteroid treatment, depot injections with testosterone improved the BMD at the lumbar spine and increased the FFM [69]. Such studies suggest that when hypogonadism is diagnosed replacement therapy is beneficial 
for the preservation of bone mass. The same recommendations should be applied to patients with COPD and postmenopausal or corticosteroid-induced hypogonadism, only after considering potential risks of such treatments.

\section{Calcitonin}

Calcitonin is a peptide hormone secreted by the $\mathrm{C}$ cells of the thyroid, which has an inhibitory effect on the osteoclasts [118]. Studies on the bone-protective effect of calcitonin have not been conclusive [43]. In a study on 44 asthmatics with severe symptoms, intra-nasal calcitonin improved BMD at the lumbar spine compared to the calcium-treated group where BMD decreased [125]. However, about one third of the patients stopped the treatment with calcitonin because of side effects and because of exacerbations of asthma [125].

\section{Bisphosphonates}

Bisphosphonates are metabolically stable analogues of pyrophosphate with affinity for the hydroxyapatite in the bone, where they inhibit the action of osteoclasts, and therefore inhibit bone resorption [126]. A few studies have assessed the effect of different bisphosphonates on the preservation of BMD in patients with chronic lung disease, most of which received corticosteroid treatments (table 3 ).

In 28 asthmatics receiving inhaled beclomethasone 2-2.2 mg. day $^{-1}$, treatment with calcium supplements $\left(1000 \mathrm{mg} \cdot \mathrm{day}^{-1}\right)$ or cyclical etidronate $400 \mathrm{mg} \cdot \mathrm{day}^{-1}$ in addition to calcium $1000 \mathrm{mg} \cdot \mathrm{day}^{-1}$ for $18 \mathrm{months,} \mathrm{equally}$ improved BMD compared to a group where no supplements were given [127]. In another study the effect on BMD of cyclical etidronate for 12 months was compared with calcium supplements $\left(500 \mathrm{mg} \cdot \mathrm{day}^{-1}\right)$ in patients who continued oral corticosteroid treatment (at least $10 \mathrm{mg} \cdot \mathrm{day}^{-1}$ ) [128]. Etidronate improved BMD at the lumbar spine by $5.7 \%$ and total hip by $6.8 \%$, while the calcium supplemented group lost $3.4 \%$ BMD at the lumbar spine and $4.1 \%$ at the total hip [128]. In 15 patients with asthma and two with sarcoidosis treated with prednisolone for a range of 3-30 yrs, with a range of doses between 7.5 and $40 \mathrm{mg} \cdot \mathrm{day}^{-1}$, treatment with $30 \mathrm{mg}$ of pamidronate every 3 months for $1 \mathrm{yr}$ produced a mean gain in BMD at the lumbar spine of $3.4 \%$ without any change at the femoral neck [129].

Two studies on greater number of patients, one on 60 with chronic asthmatic bronchitis treated with inhaled beclomethasons or fluticasone [130] and another on 74 patients with asthma treated with oral and inhaled corticosteroids [131], reported improvement in BMD after 12 months treatment with clodronate. Another study on females with asthma $(n=70)$ or COPD $(n=8)$ receiving between $800 \mu \mathrm{g}$ and $>1600 \mu \mathrm{g}$ inhaled corticosteroid treatment (and 50\% intermittent additional oral corticosteroid treatment) assessed the effect of oral alendronate $10 \mathrm{mg} \cdot \mathrm{day}^{-1}$ and calcium supplements $\left(500 \mathrm{mg} \cdot \mathrm{day}^{-1}\right)$ compared to placebo and calcium supplements $\left(500 \mathrm{mg} \cdot \mathrm{day}^{-1}\right)$ [132]. While the placebo and calcium-treated groups lost a mean $0.8 \%$ BMD at the spine and 0.37 at the hip, the alendronate group gained $3 \%$ and $1.6 \%$ BMD, respectively [132].

In adults with cystic fibrosis and $\mathrm{BMD}<2.0$ at inclusion in the study (some on long-term treatment with oral corticosteroids), treatment with $30 \mathrm{mg}$ pamidronate every 3 months and calcium supplements $\left(1000 \mathrm{mg} \cdot \mathrm{day}^{-1} ; \mathrm{n}=13\right)$ was compared with calcium supplements only $(n=15)$ [133]. After 6 months the mean $(95 \% \mathrm{CI})$ gain of BMD in the pamidronate group compared with the calcium-supplemented group was
$5.8(2.7-8.9) \%$ at the lumbar spine and $3.0(0.3-5.6) \%$ at the hip, while there was a reduction of BMD at the distal forearm of $1.7(0.3-3.7) \%$. Patients who were not treated with coticosteroids while they received pamidronate, frequently experienced bone pain. Another randomised, controlled, nonblinded trial compared the effect of $30 \mathrm{mg}$ i.v. pamidronate every 3 months for 2 yrs with vitamin D $\left(800 \mathrm{IU} \cdot \mathrm{day}^{-1}\right)$ and calcium supplements $\left(1000 \mathrm{mg} \cdot \mathrm{day}^{-1}\right)$ with the same doses of vitamin $\mathrm{D}$ and calcium in 34 adults with cystic fibrosis following lung transplantation [134]. Post-transplantation patients received immunosuppressants which included cyclosporin A, prednisolone and azathioprine. BMD increased by a mean \pm SD $8.8 \pm 2.5 \%$ at the spine and $8.2 \pm 3.8 \%$ at the femur in patients treated with pamidronate, compared to $2.6 \pm 3.2 \%$ and $0.3 \pm 2.2 \%$ respectively, for the vitamin $\mathrm{D}$ and calcium group $(\mathrm{p}<0.015)$.

The British Thoracic Society has recently completed a prospective multicentre placebo-controlled trial in over 700 patients treated for asthma with oral and/or inhaled corticosteroids comparing etidronate, calcium supplementation and the combination of etidronate with calcium supplementation over 5 yrs. The results of this trial are expected in the near future.

\section{Prevention and therapy: suggestions for the future}

In order to assess the efficacy of treatments, more information on the risk factors and the pathogenesis of COPD-induced osteoporosis is needed. Such information could be gathered through prospective studies designed to assess the rate of decline of the BMD and the contributing factors such as the type of corticotherapy, the presence of hypogonadism, ongoing smoking, reduced physical activity and the weakness of the skeletal muscles.

In view of the relationship between the skeletal muscle mass and the BMD [50, 51, 87, 88] it is likely that training programmes and conditioning will have beneficial effects on the maintenance of BMD in patients with COPD. However, the types of training and the specific programmes of rehabilitation need to be designed.

Hormone replacement therapy is likely to be beneficial in patients with COPD and hypogonadism. In view of the age group and exposure to corticosteroid treatment, which are associated with hypogonadism, the assessment of the hormonal status should be part of the general investigation of osteoporosis in patients with COPD.

The intake of calcium and vitamin D should be assessed, in view of some reports that supplementation is beneficial for the preservation of the bone mass, mainly in subjects with a reduced intake [118-120]. According to the current nutritional recommendations the daily intake of calcium $\left(1,200-1,500 \mathrm{mg} \cdot \mathrm{day}^{-1}\right)$ and vitamin D (at least $\left.400 \mathrm{IU} \cdot \mathrm{day}^{-1}\right)$ should be ensured [43, 80, 121].

More promising in view of the available research in patients with chronic lung disease is the therapy with bisphosphonates. The patients with COPD and osteoporosis treated with longterm systemic corticosteroids should be considered for such treatments. For patients with osteopenia, those on long-term inhaled corticosteroids and/or intermittent courses of oral corticosteroids without florid osteoporosis, regular monitoring of BMD by DXA scanning should be undertaken.

\section{Suggested future research}

Prospective studies on the incidence of osteoporosis and osteopenia in COPD will need to assess patients with all degrees of disease severity, including those with mild 


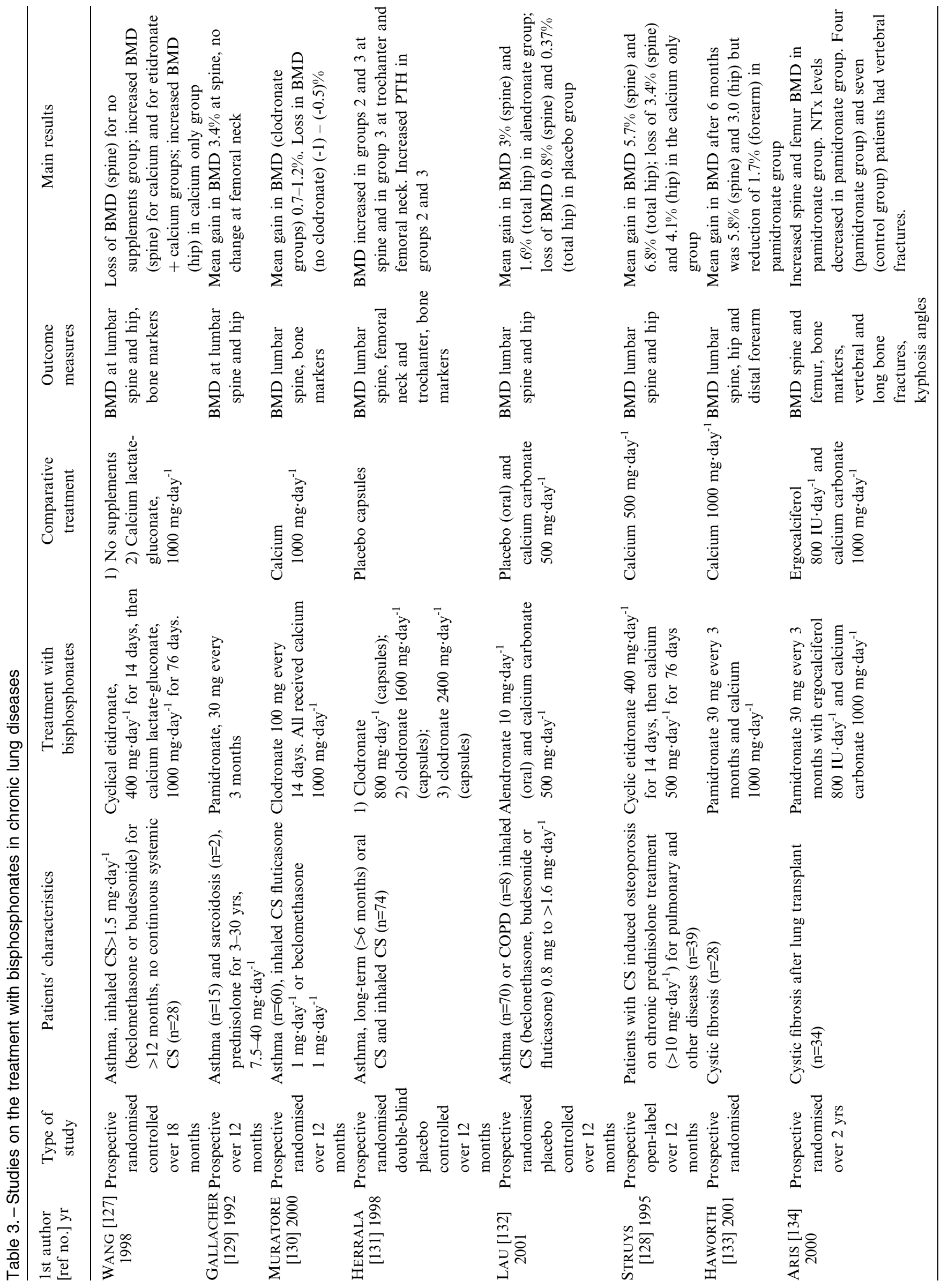


impairment of the lung function, which would allow assessment of patients who have not been exposed to corticosteroid treatments. Such longitudinal studies should investigate the contribution of potential factors leading to osteoporosis such as the nutrition, smoking, levels of physical activity, body habitus and composition, peripheral skeletal muscle mass and function.

Future research will explore the incidence of hypogonadism in patients with COPD and if hormone manipulation has long-term effects on the preservation of bone mass. Other possible hormonal changes will need to be investigated, such as the potential imbalance between anabolic (IGF-1) and catabolic (corticosteroids) hormones that may contribute to the loss of skeletal muscle and bone mass in COPD.

The relationship between the persistent systemic inflammation and the depletion of skeletal muscles and bone in some patients with COPD will need to be further explored, in order to clarify if circulating inflammatory mediators have an effect at the tissue level or if other factors stimulate increased inflammation in the peripheral tissues, including the bone tissue.

Randomised placebo-controlled trials are required to assess the effects of bisphosphonates on the prevention and treatment of osteoporosis and fractures in various groups of patients with chronic obstructive pulmonary disease (exposed to oral or inhaled corticosteroids, affected by hypogonadism, as well as those who might have low bone mineral density due to other causes). Such trials should have clear outcome measures, such as the change in bone mineral density or the assessment of the fracture rates and should investigate potential short-term and long-term side effects of the treatment.

\section{References}

1. Gross NJ. Extrapulmonary effects of chronic obstructive pulmonary disease. Curr Opin Pulm Med 2001; 7: 84-92.

2. Wouters EFM, Creutzberg EC, Schols AMWJ. Systemic effects in COPD. Chest 2002; 121: 127S-130S.

3. Eid AA, Ionescu AA, Nixon LS, et al. Inflammatory response and body composition in chronic obstructive pulmonary disease. Am J Respir Crit Care Med 2001; 164: 1414-1418.

4. Schols AMWJ, Buurman WA, Breckel AJS, Dentener MA, Wouters EFM. Evidence for a relation between metabolic derangements and increased levels of inflammatory mediators in a subgroup of patients with chronic obstructive pulmonary disease. Thorax 196; 51: 819-824.

5. DiFrancia M, Barbier D, Mege JL, Orebek J. Tumor necrosis factor-alpha levels and weight loss in chronic obstructive pulmonary disease. Am J Respir Crit Care Med 1994; 150: 1453-1455.

6. Biskobing DM. COPD and osteoporosis. Chest 2002; 121: 609-620.

7. McEvoy CE, Ensrud KE, Bender E, et al. Asociation between corticosteroid use and vertebral fractures in older men with chronic obstructive pulmonary disease. Am J Respir Crit Care Med 1998; 157: 704-709.

8. Praet JP, Peretz A, Rozenberg S, Famaey J-P, Bourdoux P. Risk of osteoporosis in men with chronic bronchitis. Osteoporosis Int 1992; 2: 257-261.

9. Anonymous . Consensus development conference: diagnosis, prophylaxis and treatment of osteoporosis. Am J Med 1993; 94: 646-650

10. Marshall D, Johnell O, Wedel H. Meta-analyses of how well measures of bone mineral density predict the occurrence of osteoporotic fractures. BMJ 1996; 312: 1254-1259.

11. Aris RM, Neuringer IP, Weiner MA, Egan TM, Ontjes D.
Severe osteoporosis before and after lung transplantation. Chest 1996; 109: 1176-1183.

12. Shane E, Silverberg SJ, Donovan D, et al. Osteoporosis in lung transplantation candidates with end-stage pulmonary disease. Am J Med 1996; 101: 262-269.

13. Dubois EF, Roder E, Dekhuijzen R, Zwinderman AE, Schweitzer DH. Dual energy X-ray absorptiometry outcomes in male COPD patients after treatment with different glucocorticoid regimens. Chest 2002; 121: 1456-1463.

14. Lung Health Study Research Group. Effect of inhaled triamcinolone on the decline in pulmonary function in chronic obstructive pulmonary disease. $N$ Engl $\mathrm{J}$ Med 2000; 343: 1902-1909.

15. Pauwels RA, Lofdahl C-G, Laitinen LA, et al. Long-term treatment with inhaled budesonide in persons with mild chronic obstructive pulmonary disease who continue smoking. $N$ Engl J Med 1999; 340: 1948-1953.

16. Riancho JA, Gonzalez Macias J, Del Arco C, Amado JA, Freijanes J, Anton MA. Vertebral compression fractures and mineral metabolism in chronic obstructive lung disease. Thorax 1987; 42: 962-966.

17. Daniell HW. Osteoporosis of the slender smoker. Arch Intern Med 1976; 136: 298-304.

18. Jensen GF. Osteoporosis of the slender smoker revisited by epidemiologic approach. Eur J Clin Invest 1986; 16: 239-242.

19. Seeman E, Melton LJ, O'allon WM, Riggs BL. Risk factors for spinal osteoporosis in men. Am J Med 1983; 75: 977-983.

20. Slemenda CW, Christian JC, Reed T, Reister TK, Williams CJ, Johnston CC. Long-term bone loss in men: effects of genetic and environmental factors. Ann Int Med 1992; 117: 286-291.

21. Sparrow D, Beausoleil NI, Garvey AJ, Roener B, Silbert JE. The influence of cigarette smoking and age on bone loss in men. Arch Environ Health 1982; 37: 246-249.

22. Slemenda CW, Hui SL, Longcope C, Johnston CC. Cigarette smoking, obesity and bone mass. J Bone Miner Res 1989; 4: 737-741.

23. Valimaki MJ, Karkkainen M, Lamberg-Allardt C, et al. Exercise, smoking and calcium intake during adolescence and early adulthood as determinants of peak bone mass. BMJ 1994; 309: 230-235.

24. Ralston SH. The genetics of osteoporosis. Q J Med 1997; 90 : 247-251.

25. Pocock NA, Isman JA, Hooper JL, Yeates MG, Sambrook PN, Eberl S. Genetic determinants of bone mass in adults: a twin study. J Clin Invest 1987; 80: 706-710.

26. Morrison NA, Qi JC, Tokita A, et al. Prediction of bone density from vitamin D receptor alleles. Nature 1994; 367 : 284-287.

27. Kobayashi S, Inoue S, Hosi T, Ouchi Y, Shiraki M, Orimo $\mathrm{H}$. Association of bone mineral density with polymorphism of the estrogen receptor gene. J Bone Miner Res 1996; 11: 306-311.

28. Murray RE, Grant SFA, Reid DM, Ralston SH. Polymorphisms of the interleukin- 6 gene are associated with bone mineral density. Osteoporosis Int 1996; 6: Suppl. 1, 89.

29. Grant SFA, Reid DM, Blake G, Herd R, Fogelman I, Ralston SH. Reduced bone density and osteoporosis associated with a polymorphic Sp1 site in the collagen type I alpha 1 gene. Nature Genetics 1996; 14: 203-205.

30. Uitterlinden AG, Grant SFA, Huang Q, et al. Sp1 binding site polymorphism in the COLIA 1 gene is associated with BMD: The Rotterdam study. Osteoporosis Int 1996; 6: Suppl. $1,124$.

31. Newnham DM. Asthma medications and their potential adverse effects in the elderly. Drug Safety 2001; 24: 10651080.

32. Hodsman AB, Toogood JH, Jennings B, Fraher LJ, Baskerville JC. Differential effects of inhaled budesonide and oral prednisolone on serum osteocalcin. J Clin Endocrinol Metab 1991; 72: 530-541.

33. Meeran K, Attersley A, Burrin J, Shiner R, Ibbertson K. 
Oral and inhaled corticosteroids reduce bone formation as shown by plasma osteocalcin levels. Am J Respir Crit Care Med 1995; 151: 333-336.

34. Kerstjens HAM, Postma DS, Van Doormaal JJ, et al. Effects of short term and long term treatment with inhaled corticosteroids on bone metabolism in patients with airways obstruction. Thorax 1994; 49: 652-656.

35. Kerstjens HAM, Brand PLP, Hughes MD, et al. A comparison of bronchodilator therapy with or without inhaled corticosteroid therapy in obstructive airways disease. $N$ Engl J Med 1992; 327: 1413-1419.

36. Egan JJ, Maden C, Kalra S, Adams JE, Eastell R, Woodcock AA. A randomized, double-blind study comparing the effects of beclomethasone and fluticasone on bone density over two years. Eur Respir $J$ 1999; 13: 1267-1275.

37. Packe GE, Douglas JG, McDonald AF, Robins SP, Reid DM. Bone density in asthmatic patients taking high dose inhaled beclomethasone dipropionate and intermittent systemic corticosteroids. Thorax 1992; 47: 414-417.

38. Hughes JA, Cory BG, Male SM, Eastell R. One year prospective open study of the effect of high dose inhaled steroids, fluticasone propionate, and budesonide on bone markers and bone mineral density. Thorax 1999; 54: 223229.

39. Brown PH, Matusiewicz SP, Shearing C, et al. Systemic effects of high dose inhaled steroids: comparison of beclomethasone dipropionate and budesonide in healthy subjects. Thorax 1993; 48: 967-973.

40. Pouw GM, Prummel MF, Oosting H, et al. Beclomethasone inhalation decreases serum osteocalcin concentrations. $B M J$ 1991; 302: 627-628.

41. Toogood JH, Jennings B, Hodsman AB, Baskerville J, Fraher LJ. Effects of dose and dosing schedules of inhaled budesonide on bone turnover. J Allergy Clin Immunol 1991; 88: $572-580$.

42. Grove A, McFarlane LC, Jackson CM, et al. Effects of short term exposures to inhaled corticosteroids on novel biochemical markers of bone metabolism. Eur J Clin Pharmacol 1996; 50: 275-277.

43. Goldstein MF, Fallon JJ, Harning R. Chronic glucocorticoid therapy-induced osteoporosis in patients with obstructive lung disease. Chest 1999; 116: 1733-1749.

44. Dimai HP, Domej W, Leb G, Lau K. Bone loss in patients with untreated chronic obstructive pulmonary disease is mediated by an increase in bone resorption associated with hypercapnia. J Bone Miner Res 2001; 16: 2132-2141.

45. American Thoracic Society and European Thoracic Society. Skeletal muscle dysfunction in chronic obstructive disease. Am J Respir Crit Care Med 1999; 159: Suppl. 4, 1-40.

46. Gosselink R, Troosters T, Decramer M. Peripheral muscle weakness contributes to exercise limitation in COPD. $\mathrm{Am}$ J Respir Crit Care Med 1996; 153: 976-980.

47. Maltais F, Simard AA, Simard C, et al. Oxidative capacity of the skeletal muscle and lactic acid kinetics during exercise in normal subjects and in patients with COPD. Am J Respir Crit Care Med 1996; 153: 288-293.

48. Frost HM. On our age-related bone loss: insights from a new paradigm. J Bone Miner Res 1997; 12: 1539-1546.

49. Evans WJ. What is sarcopenia? J Gerontol 1995; 50A: 5-8.

50. Sandler RB. Muscle strength assessments and the prevention of osteoporosis. JAGS 1989; 37: 1192-1197.

51. Henderson NK, White CP, Eisman JA. The roles of exercise and fall risk reduction in the prevention of osteoporosis. Endocrinol Metab Clin North Am 1998; 27: 369-387.

52. Frost HM. Changing views about "Osteoporoses" (a 1998 overview). Osteoporos Int 1999; 10: 345-352.

53. Scheibel A. Falls, motor dysfunction and correlative neurohistologic changes in the elderly. Clin Geriatr Med 1985; 1: 671-677.

54. Edelstein SL, Barrett-Connor E. Relation between body size and bone mineral density in elderly men and women. $\mathrm{Am}$ J Epidemiol 1993; 138: 160-169.
55. Baumgartner RN, Stauber PM, Koehler KM, et al. Associations of fat and muscle masses with bone mineral in elderly men and women. Am J Clin Nutr 1996; 63: 365-372.

56. Reid IR, Ames R, Evans MC, et al. Determinants of total body and regional bone mineral density in normal postmenopausal women-a key role of fat mass. J Clin Endocrinol Metab 1992; 75: 45-51.

57. Compston JE, Bhambhani M, Laskey MA, Murphy S, Khaw KT. Body composition and bone mass in postmenopausal women. Clin Endocrinol 1992; 37: 426-431.

58. Aloia JF, Vaswani A, Ruimei MA, et al. To what extent is bone mass determined by fat-free or fat mass? Am J Clin Nutr 1995; 6: 1110-1114.

59. Coin A, Sergi G, Beninca P, et al. Bone mineral density and body composition in underweight and normal elderly subjects. Osteoporos Int 2000; 11: 1043-1050.

60. Incalzi A, Caradonna $\mathrm{P}$, Ranieri $\mathrm{P}$, et al. Correlates of osteoporosis in chronic obstructive pulmonary disease. Respir Med 2000; 94: 1079-1084.

61. Iqbal F, Michaelson J, Thaler L, et al. Declining bone mass in men with chronic pulmonary disease: contribution of glucocorticoid treatment, body mass index, and gonadal function. Chest 1999; 116: 1616-1624.

62. Nishimura Y, Nakata H, Tsutsumi M, Maeda H, Yokoyama M. Relationship between changes of bone mineral content and twelve minute walking distance in men with chronic obstructive pulmonary disease: a longitudinal study. Int Med 1997; 36: 450-453.

63. Engelen MPKJ, Schols AMWJ, Heidendal GAK, Wouters EFM. Dual-energy X-ray absorptiometry in the clinical evaluation of body composition and bone mineral density in patients with chronic obstructive pulmonary disease. $\mathrm{Am}$ J Clin Nutr 1998; 68: 1298-1303.

64. Raisz LG. Local and systemic factors in the pathogenesis of osteoporosis. N Engl J Med 1988; 318: 818-828.

65. Falahati-Nini A, Riggs BL, Atkinson EJ, O'Fallon WM, Eastell R, Khosla S. Relative contributions of testosterone and estrogen in regulating bone resorption and formation in normal elderly men. $J$ Clin Invest 2000; 106: 1553-1560.

66. Szulc P, Munoz F, Claustrat B, et al. Bioavailable estradiol may be an important determinant of osteoporosis in men: the MINOS study. J Clin Endocrinol Metab 2001; 86: 192-199.

67. Khosla S, Melton LJ, Atkinson EJ, O'Fallon WM. Relationship of serum sex steroid levels to longitudinal changes in bone density in young versus elderly men. $J$ Clin Endocrinol Metab 2001; 86: 3555-3561.

68. Kamischke A, Kemper DE, Castel MA, et al. Testosterone levels in men with chronic obstructive pulmonary disease with or without glucocorticoid therapy. Eur Respir J 1998; 11: 41-45.

69. Reid IR, Wattie DJ, Evns MC, Stapleton JP. Testosterone therapy in glucocorticoid-treated men. Arch Intern Med 1996; 156: 1173-1177.

70. Rosen CJ, Donahue LR. Insulin-like growth factors and bone: the osteoporosis connection revisited. PSEBM 1998; 219: $1-7$.

71. Decramer M. Respiratory muscles in COD regulation of trophical status. Verh K Acad Geneeskd Belg 2001; 63: 577602.

72. Hedstrom M. Hip fracture patients, a group of frail elderly people with low bone mineral density, muscle mass and IGF1 levels. Acta Physiol Scand 1999; 167: 347-350.

73. Pacifici R, Rifas L, Teitelbaum S, et al. Spontaneous release of interleukin 1 from human blood monocytes reflects bone formation in idiopathic osteoporosis. Proc Natl Acad Sci USA 1987; 84: 4616-4620.

74. Haussler MR, McCain TA. Basic and clinical concepts related to vitamin D metabolism. $N$ Engl J Med 1992; 297: 974-982.

75. Seeman E. Pathogenesis of bone fragility in women and men. Lancet 2002; 359: 1841-1850.

76. Callahan CM, Dittus RS, Katz BP. Oral corticosteroid 
therapy for patients with stable chronic obstructive pulmonary disease. A meta-analysis. Ann Int Med 1991; 114: 216-223.

77. Davies L, Angus RM, Calverley PMA. Oral corticosteroids in patients admitted to hospital with exacerbations of chronic obstructive pulmonary disease: a prospective randomised controlled trial. Lancet 1999; 354: 456-460.

78. Canalis E. Mechanisms of glucocorticoid action in bone: implications to glucocorticoid-induced osteoporosis. J Clin Endocrinol Metab 1996; 81: 2441-3447.

79. Urena P, Iida-Klein A, Kong X-F, et al. Regulation of parathyroid hormone $(\mathrm{PTH}) / \mathrm{PTH}$-related peptide receptor messenger ribonucleic acid by glucocorticoids and PTH in ROS17/2.8 and OK cells. Endocrinology 1994; 134: 451-456.

80. Lane NE, Lukert B. The science and therapy of glucocorticoid-induced bone loss. Endocrinol Metab Clin North Am 1998; 27: 465-483.

81. Reid IR, Evans MC, Wattie DJ, et al. Bone mineral density of the proximal femur and lumbar spine in glucocorticoidtreated asthmatic patients. Osteoporosis Int 1992; 2: 103-105.

82. Sambrook PN, Birmingham J, Kempler S, Ames R, Cundy TF. Corticosteroid effects on proximal femur bone loss. J Bone Miner Res 1990; 5: 1211-1216.

83. Reid IR, Grey AB. Corticosteroid osteoporosis. Bailliere Clin Rheumatol 1993; 7: 573-587.

84. Chappard D, Legrand E, Basle MF, et al. Altered trabecular architecture induced by corticosteroids: a bone histomorphometric study. J Bone Miner Res 1996; 11: 676-685.

85. Jones A, Fay JK, Burr M, Stone M, Hood K, Roberts G. Inhaled corticosteroid effects on bone metabolism in asthma and mild chronic obstructive pulmonary disease. The Cochrane Library: 2002: CD003537.

86. Layne JE, Nelson ME. The effects of progressive resistance training on bone density: a review. Med Sci Sports Exerc 1999; 31: 25-30.

87. Aniansson A, Zetterberg C, Hedberg M, Komi PV. Impaired muscle function with ageing. A backward factor in the incidence of fractures of the proximal end of the femur. Clin Orthop Relat Res 1984; 191: 193-200.

88. Winett RA, Carpinelli RN. Potential health-related benefits of resistance training. Preventive Med 2001; 33: 503-513.

89. Schols AM, Slangen J, Volovics L, et al. Weight loss is a reversible factor in the prognosis of chronic obstructive pulmonary disease. Am J Respir Crit Care Med 1998; 157: 1791-1797.

90. Engelen MP, Schols AM, Does JD, Wouters EF. Skeletal muscle weakness is associated with wasting of extremity fatfree mass but not with airflow obstruction in patients with chronic obstructive pulmonary disease. Am J Clin Nutr 2000; 71: 733-738

91. Marquis K, Debigare R, Lacase Y, et al. Midthigh muscle cross-sectional area is a better predictor of mortality than body mass index in patients with chronic obstructive pulmonary disease. Am J Respir Crit Care Med 2002; 166: 809-813.

92. Mostert R, Goris A, Welling-Sheepers, Wouters EF, Schols AM. Tissue depletion and health related quality of life in patients with chronic obstructive pulmonary disease. Respir Med 2000; 94: 859-867.

93. Mohan S, Baylink DJ. Characterisation of the IGF regulatory system in bone. In: Current Directions in Insulin-Like Growth Factor Research. LeRoith D, Raizada MK, Eds. New York, Plenum Press, 1994; pp. 397-406.

94. Niholas V, Prewett A, Beltica P, et al. Age-related declines in IGF-1 and TGF- $B$ in femoral cortical bone from men and women. J Clin Endocrinol Metab 1994; 78: 1011-1016.

95. Pfeilschifter J, Ziegler R. Relationship between IGF-1 and skeletal ageing. Eur J Endocrinol 1998; 138: 617-618.

96. Jenkins RC, Ross RJ. Growth hormone therapy for protein catabolism. QJM 1996; 89: 813-819.

97. Schols AMWJ, Buurman WA, van den Breckel ASJ, Denter MA, Wouters EFM. Evidence of a relation between metabolic derangements and increased levels of inflammatory mediators in a subgroup of patients with chronic obstructive pulmonary disease. Thorax 1996; 51: 819-824.

98. Schols AM, Creutzberg EC, Buurman WA, Campfield LA, Saris WH, Wouters EFM. Plasma leptin is related to proinflammatory status and dietary intake in patients with chronic obstructive pulmonary disease. Am J Respir Crit Care Med 1999; 160: 1220-1226.

99. de Godoy I, Donahoe M, Calhoun WJ, Mancino J, Rogers RM. Elevated TNF- $\alpha$ production by peripheral blood monocytes of weight-losing COPD patients. Am J Respir Crit Care Med 1996; 153: 633-637.

100. Gowen M, Mundy GR. Actions of recombinant interleukin 1 , interleukin 2 and interferon $\gamma$ on bone resorption in vitro. J Immunol 1986; 136: 2478-2482.

101. Bertolini DR, Nedwin GE, Bingman TS, Smith DD, Mundy GR. Stimulation of bone resorption and inhibition of bone formation in vitro by human tumour necrosis factor. Nature 1986; 319: 516-518.

102. Manolagas SC, Jilka RL. Bone marrow, cytokines and bone remodelling. $N$ Engl J Med 1995; 332: 305-311.

103. Anker SD, Clark AL, Teixeira MM, Hellewell PG, Coates AJS. Loss of bone mineral in patients with cachexia due to chronic heart failure. Am J Cardiol 1999; 83: 612-615.

104. Ionescu AA, Nixon LS, Evans WD, et al. Bone density, body composition and inflammatory status in cystic fibrosis. Am J Respir Crit Care Med 2000; 162: 789-794.

105. Espat NJ, Moldawer LL, Copeland EM. Cytokine-mediated alterations in host metabolism prevent nutritional repletion in cachectic cancer patients. J Surg Oncol 1995; 58: 77-82.

106. Cooper C, Barker DJP, Wickham C. Physical activity, muscle strength, and calcium intake in fracture of the proximal femur in Britain. BMJ 1988; 297: 1443-1446.

107. Mussolino ME, Looker AC, Madans JH, Langlois JA, Orwoll ES. Risk factors for hip fracture in white men: the NHANES I epidemiologic follow-up study. J Bone Miner Res 1998; 13: 918-924.

108. Van Staa TP, Leufkens HGM, Abenhaim L, Zhang B, Cooper C. Use of oral corticosteroids and risk of fractures. $J$ Bone Miner Res 2000; 15: 993-1000.

109. Johnston CC, Melton LJ, Lindsay R, Eddy DM. Clinical indications for bone mass measurements. $J$ Bone Miner Res 1989; 4: Suppl. 2, 1-28.

110. Cooper C, Coupland C, Mitchell M. Rheumatoid arthritis, corticosteroid therapy and hip fracture. Ann Rheum Dis 195: 54: 49-52.

111. Van Staa TP, Leufkens HGM, Cooper C. Use of inhaled corticosteroids and risk of fractures. J Bone Miner Res 2001; 16: $581-588$.

112. Adinoff AD, Hollister JR. Steroid-induced fractures and bone loss in patients with asthma. N Engl J Med 1983; 309: 265-268.

113. Marshall D, Johnell O, Wedel H. Meta-analysis of how well measures of bone mineral density predict occurrence of osteoporotic fractures. BMJ 1996; 312: 1254-1259.

114. Luengo M, Picada C, Del Rio LD, Guanabens N, Montserrat JM, Setoain J. Vertebral fractures in steroid dependent asthma and involutional osteoporosis: a comparative study. Thorax 1991; 46: 803-806.

115. Leech JA, Dulberg C, Kellie S, Pattee L, Gay J. Relationship of lung function to severity of osteoporosis in women. Am Rev Respir Dis 1990; 141: 68-71.

116. Walker-Bone K, Arden N, Cooper C. Epidemiological aspects of osteoporosis. Rev Contemp Pharmacother 1998; 9: 225-231.

117. Advisory Group on Osteoporosis. Report. London, Department of Health 1994.

118. Eastell R. Treatment of postmenopausal osteoporosis. $N$ Engl J Med 1998; 338: 736-746.

119. Heikinheimo RJ, Inkovara JA, Harju EJ, et al. Annual injection of vitamin D and fractures of aged bones. Calcif Tissue Int 1992; 51: 105-110. 
120. Chapuy MC, Arlot ME, Delmas PD, Meunier PJ. Effect of calcium and cholecalciferol treatment for three years on hip fractures in elderly women. BMJ 1994; 308: 1081-1082.

121. American College of Rheumatology: recommendations for the prevention and treatment of glucocorticoid-induced osteoporosis. Arthritis Rheum 1996; 39: 1291-1801.

122. Kiel DP, Felson DT, Anderson JJ, Wilson PWF, Moskowitz MA. Hip fracture and the use of estrogens in postmenopausal women: The Framingham study. N Engl J Med 1987; 317: 1169-1174.

123. Paganini-Hill A, Ross RK, Gerkins VR, Henderson BE, Arthur M, Mick TM. Menopausal estrogen therapy and hip fractures. Ann Intern Med 1981; 95: 28-31.

124. Lukert BP, Johnson BE, Robinson RG. Estrogen and progesterone replacement therapy reduces glucocorticoidinduced bone loss. J Bone Miner Res 1992; 7: 1063-1069.

125. Luengo M, Pons F, Martinez de Osaba MJ, Picado C. Prevention of further bone loss by nasal calcitonin in patients on long-term glucocorticoid therapy for asthma: a two year follow up study. Thorax 1994; 49: 1099-1102.

126. Ebetino FH, Francis MD, Rogers MJ, Russell RGG, Lam KS. Mechanisms of action of etidronate and other bisphosphonates. Rev Contemp Pharmacother 1998; 9: 233-243.

127. Wang WQ, Ip MS, Tsang KW, et al. Antiresorptive therapy in asthmatic patients receiving high-dose inhaled steroids: a prospective study for 18 months. J Allergy Clin Immunol 1998; 101: 445-450.
128. Struys A, Snlder AA, Mulder H. Cyclical etidronate reverses bone loss of the spine and proximal femur in patients with established corticosteroid-induced osteoporosis. Am J Med 1995; 99: 235-241.

129. Gallacher SJ, Fenner JA, Anderson K, et al. Intravenous pamidronate in the treatment of osteoporosis associated with corticosteroid dependent lung disease: an open pilot study. Thorax 1992; 47: 932-936.

130. Muratore M, Santacesaria G, Quarta E, Calcagnile F, Cosentino L, Muratore L. Prevention with clodronate of osteoporosis secondary to inhaled corticosteroid treatment in patients with chronic asthmatic bronchitis. Int $J$ Clin Pharmacol Res 2000; 20: 61-64.

131. Herrala J, Poulijoki H, Lippo K, et al. Clodronate is effective in preventing corticosteroid-induced bone loss among asthmatic patients. Bone 1998; 22: 577-582.

132. Lau EMC, Woo J, Chan YH, Li M. Alendronate for the prevention of bone loss in patients on inhaled steroid therapy. Bone 2001; 29: 506-510.

133. Haworth CS, Selby PL, Adams JE, Mawer EB, Harrock $\mathrm{AW}$, Webb AK. Effect of intravenous pamidronate on bone mineral density in adults with cystic fibrosis. Thorax 2001; 56: $314-316$

134. Aris RM, Lester GE, Renner JB, et al. Efficacy of pamidronate for osteoporosis in patients with cystic fibrosis following lung transplantation. Am J Respir Crit Care Med 2000; 162: 941-946. 